\title{
OS PRINCÍPIOS FUNDAMENTAIS DE RATKE E DE COMÊNIO PARA A UNIVERSALIZAÇÃO DO ENSINO ESCOLAR
}

\author{
Sandra Garcia Neves \\ UEM \\ sandragarcianeves@bol.com.br1 \\ João Luiz Gasparin \\ UEM \\ gasparin01@brturbo.com.br2
}

\section{RESUMO:}

Há muito tempo educadores buscam entender antigas práticas educativas para identificar as exigências e necessidades do trabalho docente nos diferentes contextos. Objetiva-se, neste estudo, conforme abordagem da metodologia histórico-descritiva, apresentar os aforismos e alguns estudos de Wolfgang Ratke e de João Amós Comênio, bem como, as similaridades entre os estudos de um e outro autor, com o intuito de comprovar a influência de Ratke sobre Comenius. O estudo destes clássicos, na área da educação, possibilita uma percepção clarificada de como o método de ensino, naquele período, foi norteado pelo pensamento religioso, econômico, cultural e político, e que práticas educativas tais influências impuseram. Para tal percepção, fez-se necessária uma breve caracterização dos autores e seus tratados educativos conforme estudos de João Luiz Gasparin e Sandino Hoff. A idéia central deste texto é demonstrar como Comênio, na Didática Magna, manifesta muitas proposições encontradas nos princípios fundamentais do ensino de Ratke que pretendeu, com sua Arte de Ensinar, o ensino universal. Comênio sistematizou tal proposta.

Palavras-chave: Universalização do Ensino. Princípios educativos. Método didático.

\section{THE FUNDAMENTAL PRINCIPLES OF RATKE AND COMENIUS FOR UNIVERSAL EDUCATION}

\begin{abstract}
:
For many years educators have tried to understand ancient educational practices in order to identify the requirements and needs of teaching in different contexts. Following the historical-descriptive methodology approach, it is the goal of this study to present aphorisms and some studies of Wolfgang Ratke and those of Jan Amos Comenius, as well as the similarities between their works, in order to prove Ratke's influence on Comenius. The study of these classics in the field of education enables a clear perception of how the teaching method in that period was guided by a religious, economic, cultural and political thinking, and what educational practices such influences imposed. For this perception, it was necessary a brief characterization of the authors and their educational treaties in accordance with João Luiz Gasparin's and Sandino Hoff's studies. The core idea of this paper is to demonstrate how Comenius, in his Didactics Magna, expresses many propositions found in the fundamental principles of Ratke, who aimed, with his Art of Teaching, at universal education. Comenius systematized such a proposition.

Keywords: Universal Education. Educational principles. Teaching method.
\end{abstract}




\section{Introdução}

Permeadas pela religiosidade e pelo pensamento burguês, a "Nova Arte de Ensinar" de Wolfgang Ratke e a "Didática Magna ou Arte Universal de Ensinar Tudo a Todos" de João Amós Comênio representam as primeiras modificações do modelo educativo característico do sistema feudal para um novo modelo educativo mais próprio para nova sociedade burguesa.

Em linhas gerais, a Arte de Ensinar de Ratke caracteriza-se pela presença da religião no currículo escolar; pelos princípios encontrados na natureza; defesa do ensino pela língua materna; organização metódica; aprendizagem por meio da experiência e ensino universal com base na disciplina familiar e escolar.

A "Didática Magna ou Arte Universal de Ensinar Tudo a Todos" de Comênio fundamenta-se, principalmente, na formação por meio da instrução, da moral e da religião; no ensino universal ordenado pelas leis da natureza na aprendizagem fácil, sólida, rápida e disciplinada e na organização universal das escolas.

No Brasil, estudos expressivos referentes à pedagogia de Ratke e de Comênio são feitos pelo professor Gilberto Luiz Alves (2005), pelo professor Sandino Hoff (2008)e pelo professor João Luiz Gasparin (1992). Conforme esses educadores, o estudo dos clássicos é a base para o entendimento do ensino na atualidade.

Nesse artigo objetiva-se demonstrar como a Arte de Ensinar de Ratke se fez presente na Arte Universal de Ensinar Tudo a Todos de Comênio e salientar os elementos que constituem os métodos de ensino de ambos.

\section{Ratke e Comênio: educação universal e a sistematização do discurso pedagógico}

Em seus estudos, o pedagogo alemão Wolfgang Ratke "procurou descobrir a ordem natural na qual a mente da criança aprende", e, "de acordo com esse princípio organizou o seu método de ensino". No ano de 1612, lançou o Memorial de Frankfurt-am-Man e expôs suas ideias políticas e pedagógicas num texto composto basicamente por: "[...] a) uma reforma de ensino das línguas; b) uma reforma da instrução pública; c) uma reforma da vida política e religiosa na Alemanha". Nos oito anos em que viveu em Amsterdam, "compreendeu melhor a importância do papel da língua nacional para o desenvolvimento humano porque ali se desenvolvia o cultivo da língua neerleandesa" (HOFF; CARDOSO, 2008, p. 01).

Cômenio conhecia muito bem o método de ensino de Ratke, que "foi absorvido e incorporado comenianamente à Didáctica Magna" (GASPARIN, 1992, p. 252. Grifo do autor) e estendia-se a todas as línguas, artes e ciências. "Da mesma forma, portanto, que as pretensões de Bacon e de Comênio, seu método também é universal" e é expresso em seus vinte e cinco artigos e retomado em seus vinte e seis aforismos referentes à sua doutrina, à organização do ensino, à didática geral e à relação professor-aluno.

O nascimento da Pedagogia Moderna leva à percepção de que em João Amós Comênio encontram-se dispositivos fundantes das novas relações educativas relacionadas à simultaneidade, à graduação e à universalização. A Didática Magna foi uma tentativa de Comênio responder aos desafios postos à educação pela Modernidade e expressa "a origem do pensamento moderno" (NARODOWSKI, 2001, p. 14). Comênio

[...] assumiu a necessidade histórica de uma instituição educacional especializada destinada a 'ensinar tudo a todos'; estabeleceu os contornos gerais de sua proposta e fez as primeiras indicações dos procedimentos mais adequados à sua realização (ALVES, 2005, p. 5). 
Por ser professor e pastor, Comênio expôs sua concepção religiosa, filosófica e educativa para orientar os professores no trabalho pedagógico:

A concepção pedagógica de Comenius baseia-se num profundo ideal religioso que concebe o homem e a natureza como manifestações de um preciso desígnio divino. Para Comenius, Deus está no centro do mundo e da própria vida do homem. Com esta base se esclarece a forte carga religiosa que atravessa seus projetos de reforma da sociedade e da escola, assim como seu ideal irênico de pacificação entre os homens e a própria referência à liberdade das Igrejas em vista da constituição de um cristianismo universal (CAMBI, 1999, p. 286).

Comênio considerou inadequado o processo educativo de sua época, o que o levou a formular sua Didática num modelo educativo universal, pois não havia livros e textos adequados e o ensino era pouco atraente para as crianças. Acreditava que "o conhecimento adequado do mundo [dependia] do cultivo dos sentidos, bem como de uma relação adequada da linguagem com a experiência" (NARODOWSKI, 2001, p. 21). Propôs uma ação educadora com mecanismos racionais planejados para esse fim.

\section{Os princípios fundamentais de Ratke e Comênio para a universalização do ensino}

A universalização do ensino, abordada por Comênio, também foi tema dos estudos e propostas de Ratke. Influenciado por esse, Comênio discorreu, tanto na Pampaedia quanto na Didática Magna, sobre os fundamentos de sua Pedagogia Moderna.

Com o objetivo de identificar tais fundamentos, apresentam-se com encaminhamento da metodologia de pesquisa histórico-descritiva, os princípios educativos de Rakte que, segundo Comênio, foi um dos homens que se ocupou com um método mais fácil de ensinar as línguas e as artes.

A pretensão de Comênio (1957, p. 145) foi

[...] que se [ensinassem] a todos a conhecer os fundamentos, as razões e os objectivos de todas as coisas principais, das que existem na natureza como das que se fabricam, pois somos colocados no mundo, não sòmente para que façamos de espectadores, mas também de actores.

Ratke foi um representante do pensamento burguês e visou proporcionar educação para todos no trabalho pedagógico organizado a partir de uma nova sociedade. Acreditava que o velho pensamento social e escolar devia ser substituído pelo novo. "Seus textos revelam o pensamento burguês a combater e a eliminar o pensamento feudal" (HOFF, apud RATKE, 2008, p. 5). Mas, segundo Alves (2005, p. 63), “[...], foi Comenius quem anunciou, claramente, a proposta de escola moderna, cuja organização do trabalho didático, por inspirar-se na manufatura burguesa, representou, também, a superação definitiva do ensino artesanal". Na Didática Magna, Comênio (1957, p. 45) propôs o Tratado da Arte Universal de Ensinar Tudo a Todos ou:

processo seguro e excelente de instituir, em todas as comunidades de qualquer Reino cristão, cidades e aldeias, escolas tais que toda a juventude de um e de outro sexo, sem exceptuar ninguém em parte alguma, possa ser formada nos estudos, educada nos bons costumes, impregnada de piedade, e, desta maneira, possa ser, nos anos da 
puberdade, instruída em tudo o que diz respeito à vida presente e à futura, com economia de tempo e de fadiga, com agrado e com solidez.

Para Comênio, devido à brevidade da vida, não seria possível ensinar tudo a todos nas escolas, contudo, defendia a ideia de que todos os homens fossem dirigidos para os mesmos fins: a sabedoria, a moral e a perfeição. Desse modo, "as escolas [seriam] oficinas de humanidade, contribuindo, em verdade, para que os homens se [tornassem] verdadeiramente homens", ou seja, "sábios na mente, prudentes nas acções e piedosos no coração". Os requisitos para a verdadeira educação do homem para alcançar a vida eterna seriam: a instrução, a virtude e a piedade. Considerava que "todos aqueles que nasceram homens, nasceram para o mesmo fim principal, para serem homens, ou seja, criatura racional, senhora das outras criaturas, imagem verdadeira do seu Criador". Comênio (1957, p. $119 ; 139$; 146) salientava que "o homem é um «animal educável», pois não pode tornarse homem a não ser que se eduque". O homem se torna verdadeiramente homem, quando aprende a agir como homem, isto é, adquire as virtudes que o fazem homem.

$\mathrm{Na}$ defesa da necessidade de ensinar tudo a todos, Comênio (1957, p. 142) propôs a instrução das mulheres para a honestidade e beatitude e para as coisas que contribuíssem com a administração da vida familiar e a promoção da própria salvação e de toda a família. Na Pampaedia, Comênio recomendou uma "educação universal de todo o gênero humano" para "que todos [fossem] educados em todas as coisas e totalmente". "Todos" para Comênio (1971, p. 37; 39. Grifo do autor) significa que "todas as Nações, Estados, Famílias e Pessoas" teriam acesso "à educação universal, mediante a qual se procura conseguir tudo o que é possível para assegurar, sob o céu, o maior esplendor do homem, imagem de Deus" e "educados para a verdade, pela qual cada um, rectamente formado, escape aos precipícios do erro e do acaso, seguindo os caminhos da rectidão". A proposta de Comênio foi de

[...] uma organização para a atividade de ensino, no interior da escola, que visava equipará-la à ordem vigente nas manufaturas, em que a divisão do trabalho permitia que diferentes operações, realizadas por trabalhadores distintos, se desenvolvessem de forma rigorosamente controlada, segundo um plano prévio e intencional que as articulava, para produzir mais resultados com economia de tempo, de fadiga e de recursos (ALVES, 2005, p. 65).

Sobre a presença da religiosidade na pretensão educativa universal de Comênio, Cambi (1999, p. 286) afirma que

toda a construção pedagógica de Comenius é, de fato, caracterizada por uma forte tensão mística que sublinha seu caráter ético-religioso e a decidida conotação utópica: a educação neste quadro é a criação de um modelo universal de "homem virtuoso", ao qual é confiada a reforma geral da sociedade e dos costumes.

A formação na virtude envolveria a todos, pois, todos seriam enviados às escolas, fossem nobres ou plebeus, ricos ou pobres, rapazes ou raparigas, em todas as cidades e aldeias. Ao propor o Ensino Universal, Comênio partiu da constatação de que até sua época não havia um método de ensino certo, rápido e sólido por isso seu método era de interesse dos pais, dos professores, dos estudantes, das escolas, dos Estados e da Igreja. Preocupava-se em apresentar um método de ensino que suprisse as necessidades daqueles que não tinham condições de contratar preceptores para educar seus filhos. 
No intuito de apresentar as bases do método educativo de Ratke e demonstrar como esse influenciou a Didática Comeniana, apresentam-se os Aforismos e alguns outros estudos de Ratke relacionando-os ao que foi abordado na Didática Magna e Pampaedia. Objetiva-se demonstrar, como Comênio incorporou as ideias pedagógicas de Ratke nos tratados referidos.

Nos princípios de Ratke, seu empenho religioso é percebido já de início quando salienta que "tudo [deveria ser] precedido de uma prece" e que "a primeira instrução, [...] geral ou particular, [seria a] religiosa". Para Ratke (2008, p. 47; 60) "antes de tudo, o aluno [seria] instruído nas coisas de Deus", pois considerava tal ensinamento mais nobre e precioso, por isso, mereceria atenção primária. A partir daí o ensino seria repleto de graça e proveito. Comênio, de igual modo, iniciou a exposição da Didática Magna com esclarecimentos acerca da educação da juventude conforme os ensinamentos da Sagrada Escritura.

Diante dos problemas enfrentados em sua época, Comênio (1957, p. 67; 130) defendeu a possibilidade de se evitar a corrupção do gênero humano por meio da educação sensata e prudente da juventude. O homem seria embebido, desde os primeiros anos de vida, dos preceitos saudáveis à vida. Se assim não fosse, os sentidos externos não desempenhariam seu papel e a alma humana se ocuparia de coisas inúteis e prejudiciais, difíceis de desaprender. Em suas palavras,

educar, pois, pròvidamente a juventude é providenciar para que os espíritos dos jovens sejam preservados das corruptelas do mundo e para que as sementes de honestidade neles lançadas sejam, por meio de admoestações e exemplos castos e contínuos, estimuladas para que germinem felizmente, e, por fim, providenciar para que as suas mentes sejam imbuídas de um verdadeiro conhecimento de Deus, de si mesmas e da multiplicidade das coisas; para que se habituem a ver a luz de Deus, e a amar e a venerar, acima de tudo, o Pai das luzes (COMÊNIO, 1957, p. $67)$.

A juventude estava habituada a conviver com bons e maus exemplos, contudo, estes eram em maior número e faziam com que os bons exemplos fossem ineficazes. Ao crescer sem a devida cultura e distante da virtude, a juventude adquiria costumes e hábitos grosseiros, depravados e confusos. Por esses motivos, Comênio (1957, p. 178) defendeu que a educação da infância norteasse os espíritos por toda a vida, pois, "o melhor momento para remediar as deficiências e os excessos das inteligências, [seria] quando [fossem] novas".

Outro problema percebido por Comênio (1957, p. 136) referente à sua época foi que "raramente os pais [estavam] preparados para educar bem os filhos, ou raramente [dispunham] de tempo para isso, daí se segue como consequência que [haveriam] pessoas que [fizessem] apenas isso como profissão e desse modo [servissem] a toda a comunidade". Em complemento, propôs o regime de colaboração entre os alunos, que fossem guiados por seus exemplos e regras, e que nas escolas fossem ensinadas a moral e a piedade e não somente as ciências e as artes.

Ratke (2008, p. 47; apud RIOUX, 1963, p. 283) propôs o ensino de acordo com a ordem ou o curso da natureza. Tal expressão encontra-se nos fundamentos de Comênio (1957, p. 43. Grifo do autor):

onde os fundamentos de todas as coisas que se aconselham são tirados da própria natureza das coisas; a sua verdade é demonstrada com exemplos paralelos das artes mecânicas; o curso dos estudos é distribuído por anos, 
meses, dias e horas; e, enfim, é indicado um caminho fácil e seguro de pôr estas coisas em prática com bom resultado.

Toda a Didática Magna é permeada por exemplos tirados da natureza e desses Comênio (1957, p. 47) retirou aprendizagens e ensinamentos. Acreditava que a ordem buscada para a arte de tudo ensinar e tudo aprender encontrava-se na natureza, e que, conduzido por essa, o homem aprenderia todas as coisas. Indagou: "e não poderá o homem ser fàcilmente educado naquelas coisas para as quais a natureza, não apenas o chama e conduz, mas até o atrai e arrasta?". Os fundamentos sólidos do método de ensinar e de aprender seriam buscados na natureza e realizariam os mesmos processos na realização dessas tarefas.

Para Ratke (2008, p. 47) "[...] todo ensino e toda aprendizagem antinaturais, violentos ou forçados, [seriam] prejudiciais e [enfraqueceriam] a natureza". Comênio (1957, p. 157) acrescentou que "na educação da juventude, usou-se quase sempre um método tão duro que as escolas são consideradas como os espantalhos das crianças, ou as câmaras de tortura das inteligências".

No intuito de poupar o aluno do sufoco, Ratke (Apud RIOUX, 1963, p. 59) propôs "não mais do que uma coisa por vez", pois "nada [atrapalharia] mais a inteligência do que querer aprender muitas coisas ao mesmo tempo. [Dever-se-ia], ao contrário, tomar ordenadamente uma coisa após a outra e tratar corretamente uma e depois outra [...]". Entre suas indicações, utilizar somente um autor para cada língua, estudá-lo bem e passar a outro.

No método de ensino de Ratke (Apud RATKE, 2008, p. 48) uma coisa deveria ser repetida muitas vezes. A esse princípio, Comênio (1957, p. 243) acrescentou que "nada se obrigue a aprender de cor, a não ser aquilo que a inteligência compreendeu perfeitamente. E não obrigue uma criança a recitar de cor uma lição, sem se ter a certeza de que ela a compreendeu".

Cambi (1999, p. 282) esclarece que "Ratke opõe-se à aprendizagem mnemônica, passiva e estéril, em nome de um procedimento não-construtivo da aprendizagem. Todo conhecimento deve ser atingido através da indução e da experimentação". Antes de ligar-se à palavra, dever-se-ia reportar à coisa. Para Ratke (2008, p. 50) "quando algo [fosse] bem apreendido pela inteligência, em numerosas repetições, a memória [seguiria] por si mesma sem nenhum esforço".

Ratke $(2008$, p. 48; 53; 60) propôs "tudo, a princípio, na língua materna". O aluno se concentraria unicamente nas coisas a serem aprendidas, e,

[...] quando [tivesse] compreendido bem na sua língua materna o que ele [deveria] aprender, não lhe [seria] então difícil estudar a mesma coisa em uma língua estrangeira, uma vez que livros idênticos e de mesma disposição [seriam] utilizados em todas as aulas de língua.

Os conhecimentos úteis e necessários seriam ensinados e utilizados na língua materna. Como à época de Ratke o latim era a língua universal, indicou que no ensino se procedesse "da língua materna para uma outra língua". Posto que o alemão foi sua língua materna, Ratke $(2008$, p. 49; 59) assim organizou o ensino e a aprendizagem das línguas: do alemão para o hebreu, para aprender os ensinamentos bíblicos; do hebreu para o caldeu, sírio e árabe; depois o grego para aprender os ensinamentos de Jesus Cristo, e por fim o latim. Complementou que "o grego, hebreu etc. não [deveriam] ser aprendidos, como se [fez] até o [momento], apenas se lendo o que está escrito, sem os ter falado. Aprender a qualidade própria de uma língua [dependeria] muito do aprendê-la a falar". As línguas 
seriam aprendidas a partir de sua qualidade básica, e, ensinadas pelo uso. Após aprender a gramática, as conjugações, as comparações e as derivações, o aluno se empreenderia nos exercícios que serviriam para interpretar o escritor em sua língua materna.

Outro princípio educativo de Ratke (2008, p. 49; apud RIOUX, 1963, p. 283) foi "tudo, sem coerção" que "nenhuma menina, nenhum menino [deveria] ser apavorado". Não se deveria bater no aluno para levá-lo a aprender, essa seria uma prática antinatural. Ao invés da coerção, utilizar outros métodos, pois, "[...] com a opressão e as batidas, a juventude [adquiria] desgosto do estudo e se [tornava] hostil ao ensino", e, não adquirir o hábito de bater nas crianças, mas, empreender melhor os esforços no sentido de que aprendessem tornando-se desnecessários os castigos físicos. Os alunos não pagariam injustamente o erro dos mestres que não soubessem ensinar.

Segundo Ratke (2008, p. 48) "a inteligência humana [seria] feita assim: o indivíduo [aprenderia] com alegria. Com cólera e batidas, [estragava-se] tudo", pois "o aluno não [temeria] o mestre-do-ensino, mas, o contrário, [iria amá-lo e prestar-lhe] honra". Relação possível se o mestre cumprisse bem seu papel de ensinar convenientemente o aluno e não enganá-lo. Esse teria afeto e honraria seu mestre pelo testemunho e respeito assim obtidos, ao invés de conquistado pela força.

Seriam dispostas aos alunos horas para a diversão e repouso para revigorar-lhe e não repugnar-lhe a relação com os estudos. Acreditava que mais que duas horas de aula ininterruptas tornam-se cansativas e desprazerozas, e considerava coerção o interrogatório feito pelo mestre quando o aluno ainda não havia compreendido bem o que estudava.

Para Comênio (1957, p. 164; 129), a formação nas escolas seria "sem pancadas, sem violências e sem qualquer constrangimento, com a máxima delicadeza, com a máxima doçura e como que espontaneamente". A instrução não seria motivo de açoite, pois "a criatura racional não [seria] conduzida por meio de gritos, de prisões e de bastonadas, mas pela razão".

A crítica de Comênio $(1957$, p. 164; 171) foi de que até sua época, tal método de ensino que se estendia de cinco a dez anos, poderia ser reduzido a um ano, e deixar de ser violento, obscuro, confuso e intrincado, para ser suave, claro e distinto. Recomendava "que essa mesma formação se [fizesse] sem pancadas, sem violências e sem qualquer constrangimento, com a máxima delicadeza, com a máxima doçura e como que espontaneamente". O estudo obrigado era enfadonho e inútil, além de que, as ocupações cívicas, afastavam as crianças das atrações inatas do espírito e essas perdiam o desejo pelo conhecimento. Assim, "em primeiro lugar, [...] expulsar desses jovens aquele torpor adventício, e reconduzir a natureza ao seu rigor próprio; [para regressar], então, o apetite de saber". O primeiro passo tornar a juventude apta para receber essa formação. Diferentemente, os professores tomavam o aluno como se encontrava e começavam a modelá-lo a seu modo. Se não conseguiam de imediato, enchiam-se de ira e indignação e enfureciam-se.

Para Ratke (2008, p. 50; 59) haveria "uniformidade em todas as coisas", no ensino das línguas e gramáticas, nas artes e ciências, e, o que fosse estranho a estes, excluir para evitar confusão e erro, como as palavras ambíguas e expressões duvidosas, por exemplo. Daí a exigência de utilizar sempre um termo com o mesmo sentido, para que numa obra não houvesse contradições. Propôs que "a igualdade e a repetição simétrica dos livros [fossem] utilizadas na impressão, quando [...] possível”. Seguir essa regra somente quando possível e não forçosamente.

Ratke (apud RIOUX, 1963, p. 28; 2008, p. 51; 283) propôs "tudo por indução e experiência" e, "em primeiro lugar, a coisa em si mesma, depois o modo da coisa". Ensinar a matéria e a língua e depois a regra, "nas línguas pois não existem, quase, regras que não 
tenham exceções", por esse motivo, "nenhuma língua [seria] ensinada a partir da gramática; [partir] de um autor escolhido especialmente". Advertia que "as regras não [fossem] empregadas para preparar, nem para informar, mas para confirmar". Seria "uma coisa absurda querer inculcar gramática com castigos físicos e, em seguida, ensinar a língua”, somente a prática e a experiência ensinam.

Segundo Ratke a utilização de regras seria: orientação geral conforme o autor em estudo, retomar as notas por várias vezes e em diferentes lugares. Desse modo, o aluno descobriria a regra intuitivamente, e, quando essa se apresentasse novamente, compreendêla-ia rápida e facilmente.

Comênio (1957, p. 211) afirmava que tudo o que seria aprendido pelos alunos, fosse apresentado e explicado claramente, pois criticava que

[...] mesmo nos livros que as escolas possuem, não é observada a ordem natural, de modo que venha primeiro a matéria e depois a forma. Quase por toda a parte, é o contrário que se faz: apresenta-se a ordem das coisas antes das próprias coisas, embora seja possível ordenar, quando se não tem ainda o material para ordenar.

Outro princípio pedagógico de Ratke (2008, p. 54): “tudo, por meio da experiência e da investigação por partes". Um sistema ou regra seria julgado correto por aqueles que escrevessem sobre o assunto com autoridade fundada na razão e sobre um princípio. Para Comênio (1957, p. 164) seria preciso "penetrar por si mesmo até o âmago das próprias coisas e a tirar delas conhecimentos genuínos e utilidade".

Quanto à utilização de regras no ensino, Comênio salientava que com exemplos se conduz e governa melhor o aluno na idade infantil do que com regras, pois com aqueles imita mais facilmente mesmo que não fosse ordenado.

Para Ratke (2008, p. 54) nada deveria ser ensinado fora do autor escolhido para estudo. Somente quando o estudo do autor escolhido fosse completado se passaria ao estudo de outro autor, exceto para o ensino da gramática, pois nesse caso, não seriam criados exemplos artificiais para a regra a ser estudada a partir da experiência. Os exemplos utilizados pelo professor seriam retirados do autor em estudo, e, o aluno ater-seia a esse, salvo no estudo da gramática.

Na Didática Magna, Comênio (1957, p. 278) reafirmou essa ideia ao dizer que se agiria à imitação do sol, se para cada matéria houvesse um só autor. Tal procedimento garantiria que o aluno necessitasse do professor para aprender e "quando se limita a uma única coisa, a inteligência sabe bem melhor aprofundar".

Comênio (1957, p. 288) advertiu que "todos [sabiam] que a pluralidade dos objectos distrai os sentidos. [Conseguir-se-ia], por isso, uma grande economia de fadiga e de tempo [...] se aos alunos [não se permitissem] senão os livros de texto da sua classe".

Quanto ao ensino, Ratke (2008, p. 55) sugeriu que fosse programado de duas maneiras:

[...] primeiramente, uma curta noção com que se [iniciava] o jovem aprendiz e, em seguida, um desenvolvimento mais amplo; para este desenvolvimento o mestre-de-ensino ou o próprio jovem aprendiz, se [estivesse] bem adiantado, [poderia] fazer consulta.

Para Comênio (1957, p. 186; 261; 279) "a arte de ensinar nada mais [exigiria], portanto, que uma habilidosa repartição do tempo das matérias e do método", os estudos seriam dispostos "de tal maneira que os seguintes se [baseassem] sempre nos precedentes, e os que se [faziam] primeiro [seriam] consolidados pelos que [viriam] a seguir". Em seu 
método natural, "tudo o que precede [serviria] de fundamento a tudo o que se [seguia], não [procederia] de outro modo senão assentando todas as coisas em bases sólidas". O estudo seria bem conduzido "se todas as coisas se [ensinassem] gradualmente, sem interrupções, de modo que todas as coisas aprendidas [fossem] um reforço das aprendidas ontem e uma preparação para as que [se aprenderiam]".

Quanto ao conteúdo da aprendizagem, Comênio (1957, p. 147) enumerou três espécies: os objetos de observação, como, por exemplo, o céu, a terra e as coisas que neles existem; os objetos de imitação referente à ordem encontrada por toda a parte e expressa pelos homens em suas obras; e, os objetos de fruição, o favor da divindade e suas bênçãos. Para tornar-se semelhante a essas coisas, o homem se prepararia para conhecê-las conforme se apresentassem à sua observação. Em sua percepção, a alma se constituía pelas faculdades da inteligência aberta à observação das diferenças encontradas nas coisas, vontade dirigida à escolha dessas, entre boas e prejudiciais e memória que armazenaria aquilo que se ocupara a inteligência e a vontade.

Contudo,

[...] para que estas três faculdades possam cumprir bem a sua missão, é necessário instruí-las perfeitamente em coisas que iluminem a inteligência, dirijam a vontade e estimulem a consciência, de modo que a inteligência penetre profundamente, a vontade escolha sem erro, e a consciência refira tudo àvidamente a Deus (COMÊNIO, 1957, p. 279; 147).

A inteligência, a vontade e a consciência constituiriam uma mesma alma, e não se separariam a instrução, a virtude e a piedade.

Ratke (2008, p. 55) advertiu que todo o trabalho caberia ao mestre-do-ensino, que leria e explicaria, e, ao aluno caberia aprender. Quanto aos mestres-do-ensino, Comênio (1957, p. 279) considerava "possível que um só professor [ensinasse] algumas centenas de alunos" e "que [...] assim, [seria] mais vantajoso para o professor e para os alunos". E ainda mais, "aquele [desempenharia], sem dúvida, as suas funções com tanto maior prazer quanto mais numerosos [fossem] os alunos que via diante de si [...], e quanto mais ardoroso [fosse], tanto mais atentos [tornaria] os alunos".

A escola organizada conforme os exemplos da natureza teria as mesmas facilidades que esta. Desse modo, um só professor seria suficiente para ensinar muitos alunos. Nessa organização do ensino proposta por Comênio encontram-se as indicações: divisão de dez alunos por turma; um vigia para cada turma; chefes para os vigias organizados hierarquicamente até o chefe supremo e instrução de todos os alunos ao mesmo tempo e de uma só vez. A organização exata da escola exigia a repartição do tempo, das matérias e do método.

Ratke (2008, p. 55) advertiu que ao aluno competia ouvir e permanecer calado. As indicações seriam: não falar nem questionar durante a aula, somente anotar e perguntar depois da aula; não ser interrogado nem forçado a recitar antes que fosse suficientemente instruído; não dizer nada, nem escrever, nem traduzir na aula antes que fosse o momento e o professor autorizasse; não repetir nada nem aprender nova lição, pois, poderia se equivocar, já que estudava suficientemente com o professor, no tempo necessário e sem erro.

Para Ratke (2008, p. 56; 57) "no jovem aprendiz não [haveria] nenhum preconceito". O aluno não ditaria nada ao professor, mas executaria as coisas úteis e bem formadas por ele prescritas. Orientava que "o mestre-de-ensino nada mais [faria] que ensinar; manter a disciplina [pertenceria] aos escolarcas". O professor ocupar-se-ia com as

Revista HISTEDBR On-line, Campinas, número especial, p. 215-226, mai.2010 - ISSN: 1676-2584 223 
coisas relacionadas ao ensino que seria seu papel normal. Para isso as horas de ensino e as lições eram reguladas. Acerca da organização do ensino, Comênio (1957, p. 157) afirmava que essa realidade fez com que "a maior e a melhor parte dos alunos, aborrecidos com as ciências, e com os livros, [preferiam] encaminhar-se para as oficinas dos artesãos, ou para qualquer outro género de vida". Da mesma forma, segundo Ratke (2008, p. 58), "nenhuma lição ou hora de ensino [seria] perdida". O professor substituiria as aulas, mas o aluno não.

Comênio (1957, p. 164) afirmava

\begin{abstract}
que todos se formem com uma instrução não aparente, mas verdadeira, não superficial mas sólida; ou seja, que o homem, enquanto animal racional, se habitue a deixar-se guiar, não pela razão dos outros, mas pela sua, e não apenas a ler nos livros e a entender, ou ainda a reter e a recitar de cor as opiniões dos outros, mas a penetrar por si mesmo até ao âmago das próprias coisas e a tirar delas conhecimentos genuínos e utilidade. Quanto à solidez da moral e da piedade, deve dizer-se o mesmo.
\end{abstract}

O ensino seria disposto em quatro horas por dia e consagraria exercícios públicos dirigidos por um só professor que garantiria uma formação facílima e não mais penosa cheia de fadiga, cansaço e vertigem.

Ratke (2008, p. 58) indicou que haveria "um só mestre-de-ensino por matéria". Considerava que para o jovem era mais fácil aprender com um professor com o qual já estivesse habituado. Ao tratar somente de uma matéria, o professor se tornaria um especialista por conhecer os procedimentos particulares do ensino dessa e "[obteria] de seus alunos um rendimento excelente, o que não seria possível se ele tivesse que se aplicar em várias matérias".

Entre os fundamentos para ensinar com vantajosa rapidez, Comênio (1957, p. 278), reafirmou o princípio de Ratke ao propor que imitar-se-ia o sol, se "cada escola, ou ao menos cada classe, [tivesse] um só professor" e se "todas as disciplinas e todas as línguas [fossem] ensinadas com o mesmo método".

Ratke afirmava que "os jovens aprendizes [estariam] à vista do mestre-de-ensino" em que as modificações viriam somente de sua iniciativa. Comênio (1957, p. 281) salientou que o lugar do professor em sala de aula seria na cátedra "de onde [seria] visto e ouvido por todos". Contudo, "[poderia] despertar-se e manter-se viva a atenção, não só com a ajuda dos chefes de turma e de outros encarregados de qualquer vigilância (ou seja, de estar bem atentos aos outros), mas também e, sobretudo pela acção do próprio professor" (RATKE, 2008, p. 58).

Ratke (2008, p. 58) orientava que "a disciplina escolar e a disciplina familiar [estariam] em concordância"; os pais dariam aos filhos as mesmas ordens dadas pelos professores.

Ao finalizar o estudo sobre os métodos didáticos de Ratke e Comênio notamos que ambos partem da língua materna, da organização metódica e sistemática do ensino; indicam a preocupação com a promoção da universalização do ensino e, com este, a oportunidade de um número maior de meninos e meninas ingressarem na escola. Os educados ingressariam na vida social e no sistema de produção manufatureira.

\title{
Considerações Finais
}

O estudo dos clássicos na área de educação é de grande importância quando se objetiva clarear o pensamento pedagógico nas diferentes épocas. Com características 
particulares e contextuais, a educação, e, nessa, o método pedagógico ou didático, são influenciados pelo funcionamento da vida social, cultural e econômica.

A influência da manufatura, presente nas obras dos autores citados, clarifica os motivos e mesmo a constituição de seus métodos de ensino, como por exemplo, o estabelecimento de um professor para vários alunos e a diminuição do trabalho do professor.

Retomar princípios educativos existentes há mais de 500 anos parece voltar ao passado numa busca sem sentido de práticas que não se relacionam ao contexto atual. Contudo, no estudo dos fundamentos de ensino propostos por Ratke e Comênio, nota-se que a preocupação desses com a prática de ensino existente à época, derivam da realidade por eles vivida. Mas o que isso significa? Significa, por exemplo, que professores utilizam manuais didáticos sem a preocupação de "traduzí-los para a língua materna", ou seja, constituí-los para atender as necessidades educativas específicas e contextuais.

Qual seria então o proveito tirado dos princípios educativos formulados pelos pedagogos estudados? Sem ter a intenção de enumerá-los por todos, destaca-se a busca pela educação universal do homem por completo, conforme sua natureza; sistematização do conteúdo e organização do ensino e do estudo e a valorização da experiência de acordo com sua utilidade.

A volta e a valorização dos clássicos deve ser incentivada para que os estudantes percebam como se dá a construção histórica do processo educativo e do trabalho didático. É necessário destacar ainda que o pensamento pedagógico da Idade Moderna fundamenta e influencia muitas práticas docentes e discentes na atualidade.

\section{Referências}

ALVES, Gilberto Luiz. O trabalho didático na escola moderna: formas históricas. Campinas, São Paulo: Autores Associados, 2005. (Coleção Educação Contemporânea).

CAMBI, Franco. História da pedagogia. Tradução de Álvaro Lorencini. São Paulo: Fundação Editora da UNESP (FEU), 1999.

COMÉNIO, João Amós. Didáctica Magna. Tratado da arte universal de ensinar tudo a todos. Introdução, Tradução e Notas de Joaquim Ferreira Gomes. 3. ed. Lisboa: Fundação Lisboa; Calouste Gulbenkian, 1957.

COMÉNIO, João Amós. Pampaedia - Educação Universal. Tradução por João Ferreira Gomes. Coimbra: Faculdade de Letras da Universidade de Coimbra, 1971.

GASPARIN, João Luiz. Comênio ou da arte universal e ensinar tudo a todos totalmente. São Paulo: PUCSP, 1992. (Tese de doutorado).

HOFF, Sandino; CARDOSO, Maria Angélica. A pedagogia de Wolfgang Ratke (Ratichius) - 1571 - 1635. Disponível em: www.histedbr.com.br. Acesso em: 07 jul 2008.

HOFF, Sandino. Apresentação. In: RATKE, Wolfgang. Escritos sobre A Nova Arte de Ensinar de Wolfgang Ratke. Apresentação, tradução e notas de Sandino Hoff. Campinas: Autores Associados, 2008.

NARODOWSKI, Mariano. Comenius \& a educação. Tradução de Alfredo Veiga-Neto. Belo Horizonte: Autêntica, 2001. (Coleção Pensadores \& Educação, I). 
RATKE, Wolfgang. Escritos sobre A Nova Arte de Ensinar de Wolfgang Ratke. Apresentação, tradução e notas de Sandino Hoff. Campinas: Autores Associados, 2008.

RIOUX, G. L'Oeuvre Pédagogique de Wolfgang Ratichius. Tradução de Cássio David da Silva. Paris: J. Vrin, 1963.

\footnotetext{
${ }^{1}$ Mestra pelo Programa de Pós-Graduação em Educação da Universidade Estadual de Maringá.

${ }^{2}$ Professor do Programa de Pós-Graduação em Educação da Universidade Estadual de Maringá.
}

Artigo recebido em: 16/04/2010

Aprovado para publicação em: 21/06/2010 